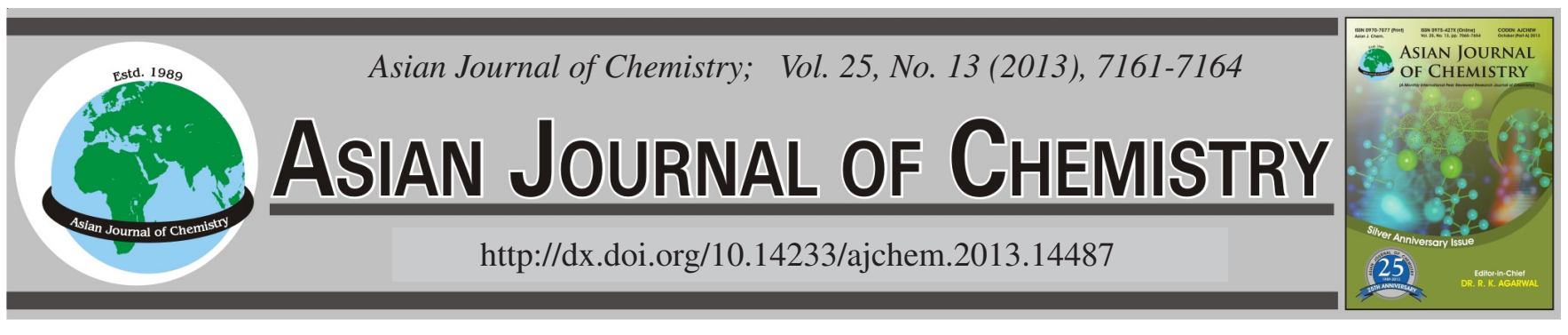

\title{
Diisopentyl Sulphide as an Extractant for Palladium(II) and the Crystal Structure of Palladium(II) Complex
}

\author{
Jiankun Xu, Zhangue Huang ${ }^{*}$ and Minguing XIE
}

Department of Chemistry, Yunnan University, Kunming 650091, P.R. China

*Corresponding author: Fax: +86 871 5032180; E-mail: zhjhuang@ynu.edu.cn

\begin{abstract}
Diisopentyl sulphide (DIS) was used in an extractant for Pd(II) from hydrochloric acid media. Palladium(II) was extracted quantitatively from $0.1 \mathrm{M} \mathrm{HCl}$ with diisopentyl sulphide in kerosene. Ammonia solution could be used as stripping agent. Extraction parameters of $\mathrm{Pd}(\mathrm{II})$, including diisopentyl sulphide concentration, contact time of aqueous and organic phases, organic/aqueous (O/A) phase ratio, ammonia concentration and hydrochloric acid concentration of aqueous phase, were studied. Diisopentyl sulphide and Pd(II) form a 2:1 adduct $\mathrm{Pd}(\mathrm{DIS})_{2} \mathrm{Cl}_{2}$ in the extraction. X-Ray crystal structure determination revealed that $\mathrm{Pd}(\mathrm{DIS})_{2} \mathrm{Cl}_{2}$ is square-planar complex in which diisopentyl sulphide acts as a neutral unidentate ligand coordinated with palladium(II) via the sulphur atom of the diisopentyl sulphide.
\end{abstract}

Key Words: Palladium, Solvent extraction, Diisopentyl sulphide.

ᄂ - - - - - - - - - - - - - - - - - - - - - - - - - - - - - - -

\section{INTRODUCTION}

Palladium is extensively used in automobile, chemical and electronic industry owing to its specific physical and chemical properties. Besides, it is also used in the field of photography and aviation ${ }^{1,2}$. Since natural resources for palladium metal are limited and the demand for palladium in industry will continue to grow, it is important to find an effective method for the recovery of palladium from secondary sources.

The hydrometallurgical methods, including solvent extraction, ion exchange resin and the reduction of palladium precipitate by reagents, are more applicable to palladium recovery ${ }^{3-5}$. In industrial process streams, palladium occurs in the divalent oxidation state and forms chloride complexes, of which the tetrachlorinated palladium anion $\left[\mathrm{PdCl}_{4}\right]^{2-}$ is the most common species. Solvent extraction has been considered as a most efficient technique for the recovery of palladium in chloride media ${ }^{6-9}$. Extensive investigations have been made to extract Pd(II) using highly selective extractants ${ }^{10-15}$. However the corresponding extractants usually have complicated molecular structures and difficult to synthesize, which hinders their further applications. In industry, it is mainly extracted by solvent extraction with straight-chain sulphide through the formation of inner-sphere complexes ${ }^{16}$.

In the present work, we have investigated the extraction of $\mathrm{Pd}(\mathrm{II})$ from hydrochloric acid medium with a diisopentyl sulphide (DIS), by controlling important parameters like extractant concentration, acidity, contact time, phase ratio and concentration of stripping agent. The crystal structure of $\mathrm{Pd}(\mathrm{DIS})_{2} \mathrm{Cl}_{2}$ showed that DIS acts as a neutral unidentate ligand coordinated with $\mathrm{Pd}(\mathrm{II})$ via the $\mathrm{S}$ atom of the DIS.

\section{EXPERIMENTAL}

A Z-2000 polarized zeeman atomic absorption spectrophotometer (Hitachi High-Technologies Corpotation, Japan) was used to measure the concentration of Pd(II). The operating conditions were carried out according to the recommendations of manufacturer. The wavelengths selected were as follows: $\mathrm{Pd} 247.6 \mathrm{~nm}$. The $\mathrm{pH}$ values were measured with a PHS-3C precision $\mathrm{pH}$ meter (REX Instrument Factory, Shanghai, China).

Pd(II) stock solution (1.0 $\left.\mathrm{g} \mathrm{L}^{-1}\right)$ : A weighed portion of palladium metal was dissolved in aqua regia $(120 \mathrm{~mL})$. When the metal was completely dissolved, the solution was evaporated to nearly dryness. Residual $\mathrm{HNO}_{3}$ was removed by adding $30 \mathrm{~mL}$ of $6 \mathrm{~mol} \mathrm{~L}{ }^{-1} \mathrm{HCI}$ and evaporated to nearly dryness again and this was repeated 3 times. The solution was transferred into a $250 \mathrm{~mL}$ of volumetric flask and the final volume was adjusted by adding $0.1 \mathrm{~mol} \mathrm{~L}^{-1} \mathrm{HCl}$ solution. The organic phases with desired extractant concentration were obtained by dissolving a definite volume of diisopentyl sulphide (DIS) in kerosene.

General extraction procedure: Equal volumes $(10 \mathrm{~mL})$ of both phases were mixed and vigorously shaken for $15 \mathrm{~min}$, which was sufficient enough to attain equilibrium in a 
preliminary experiment. After phase separation, the concentration of $\mathrm{Pd}(\mathrm{II})$ in aqueous solution was determined by an atomic absorption photometer. These results were further used to estimate the extraction efficiency of metal. The amount of extracted metal ion was calculated according to the differences in the metal concentrations of the aqueous phase between, before and after the extraction.

\section{RESULTS AND DISCUSSION}

Influences of the extractant concentration: To investigate the effect of diisopentyl sulphide (DIS) concentration on the extraction performances of $\mathrm{Pd}(\mathrm{II})$, the experiments were performed at the fixed conditions. The results are shown in Fig. 1. As can be seen from Fig. 1, DIS dissolved in kerosene with the extractant concentration varying from 0.002 to 0.02 mol L ${ }^{-1}$. The percentage extraction of $\mathrm{Pd}(\mathrm{II})$ increased in the range from 77.3 to $99.5 \%$ by increasing DIS concentration from 0.002 to $0.008 \mathrm{~mol} \mathrm{~L}^{-1}$. Further increasing DIS concentration from 0.008 to $0.02 \mathrm{~mol} \mathrm{~L}^{-1}$, the percentage extraction of Pd(II) only had a slight increase (from 99.5 to $99.9 \%$ ). $0.008 \mathrm{~mol} \mathrm{~L}^{-1}$ DIS was needed for quantitative extraction of $\mathrm{Pd}(\mathrm{II})$ from a $0.1 \mathrm{~mol} \mathrm{~L}^{-1} \mathrm{HCI}$ aqueous solution containing $100 \mathrm{mg} \mathrm{L}^{-1}$ palladium.

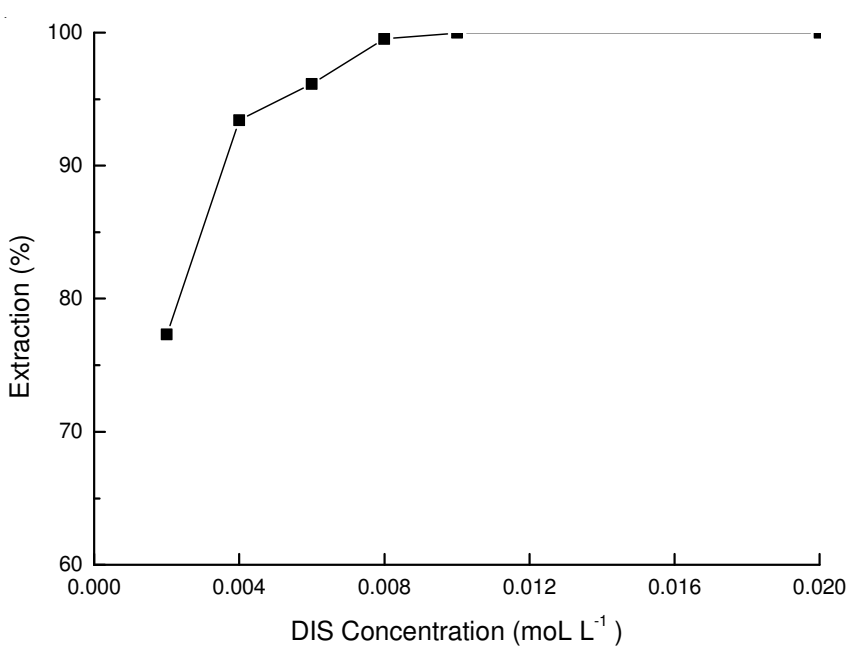

Fig. 1. Effect of extractant concentration on the extraction of $\mathrm{Pd}(\mathrm{II}) . \mathrm{C}_{\mathrm{Pd}(\mathrm{II})}$ : $100 \mathrm{mg} \mathrm{L}^{-1}, \mathrm{C}_{\mathrm{HCl}}: 0.1 \mathrm{~mol} \mathrm{~L}^{-1}, \mathrm{O} / \mathrm{A}: 1.0$, contact time: $15 \mathrm{~min}$

Influences of hydrochloric acid concentration: In industrial application for extraction of $\mathrm{Pd}(\mathrm{II})$, the acidity of stock solution usually influences significantly. The effect of hydrochloric acid concentration on the extraction of $\mathrm{Pd}(\mathrm{II})$ is shown in Fig. 2. The extraction curve indicated the percentage of extraction of $\mathrm{Pd}(\mathrm{II})$ decreased drastically with the increase of $\mathrm{HCl}$ concentration. The percentage extraction of $\mathrm{Pd}(\mathrm{II})$ decreased in the range from 99.5 to $34.5 \%$ by increase of $\mathrm{HCl}$ concentration from $0.1-2.0 \mathrm{~mol} \mathrm{~L}^{-1}$. Quantitative extraction of palladium occurred at $0.1 \mathrm{~mol} \mathrm{~L}^{-1} \mathrm{HCl}$. Therefore, $0.1 \mathrm{~mol} \mathrm{~L}^{-1}$ $\mathrm{HCl}$ was used in all subsequent experiments.

Influences of contact time: To extract Pd(II) efficiently by controlling an optimal contact time of aqueous and organic phases, the experiments were carried out with different contact time at other fixed extraction parameters. The results are shown in Fig. 3. Contact time was determined by measuring the metal

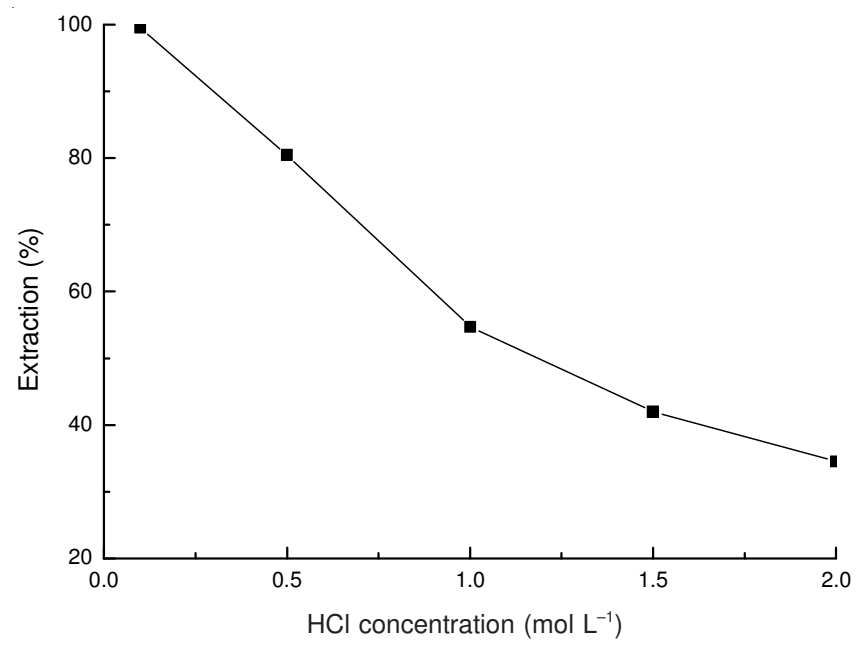

Fig. 2. Effect of $\mathrm{HCl}$ concentration on the extraction of $\mathrm{Pd}(\mathrm{II}) \mathrm{C}_{\mathrm{Pd}(\mathrm{II})}: 100$ $\mathrm{mg} \mathrm{L}^{-1}, \mathrm{C}_{\mathrm{DIS}}$ : $0.008 \mathrm{~mol} \mathrm{~L}^{-1}, \mathrm{O} / \mathrm{A}: 1.0$, contact time: $15 \mathrm{~min}$

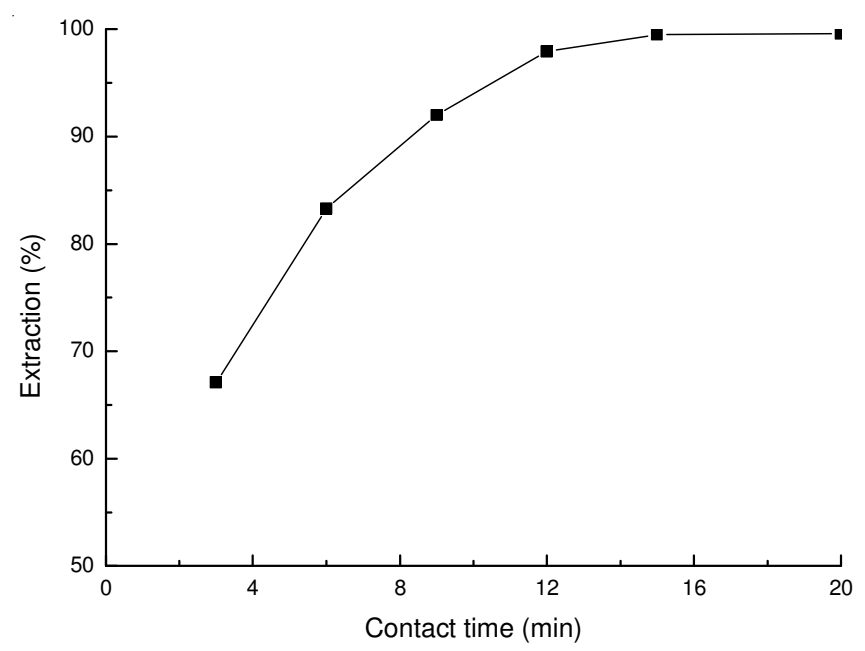

Fig. 3. Effect of contact time on the extraction of $\mathrm{Pd}(\mathrm{II}) . \mathrm{C}_{\mathrm{Pd}(\mathrm{II})}: 100 \mathrm{mg} \mathrm{L}$ ${ }^{1}, \mathrm{C}_{\mathrm{DIS}}: 0.008 \mathrm{~mol} \mathrm{~L}^{-1}, \mathrm{O} / \mathrm{A}: 1.0, \mathrm{C}_{\mathrm{HCl}}: 0.1 \mathrm{~mol} \mathrm{~L}^{-1}$

content in the aqueous phase as a function of time until the metal concentration in the aqueous solution did not vary. The two phases were shaken for a period ranging from 3 to 20 $\mathrm{min}$. The percentage extraction of $\mathrm{Pd}(\mathrm{II})$ increased in the range from 67.1 to $99.5 \%$ by in increased of contact time from 3 to $15 \mathrm{~min}$. Further increasing contact time from 15-20 min, the percentage extraction of Pd(II) kept constant. Therefore, the minimum period of equilibration required for the quantitative extraction of palladium was found to be $c a .15 \mathrm{~min}$.

Influences of organic/aqueous (O/A) phase ratio: To obtain optimal organic/aqueous phase ratio for extraction of $\mathrm{Pd}(\mathrm{II})$, the following experiments were performed at other fixed extraction parameters (Fig. 4). As can be seen from Fig. 4, by increasing organic/aqueous phase ratio from 0.4-1.0, the percentage extraction of $\mathrm{Pd}(\mathrm{II})$ increased from 90.0-99.5\%. By further increasing organic/aqueous phase ratio from 1.02.0, the percentage extraction of $\mathrm{Pd}(\mathrm{II})$ kept constant. Therefore, $\mathrm{Pd}(\mathrm{II})$ can be extracted efficiently by controlling organic/ aqueous phase ratio, 1.0.

Stripping properties of palladium: Palladium loaded in the organic phase was stripped with various stripping agents, such as nitric acid, sodium sulfite and ammonia as stripping 


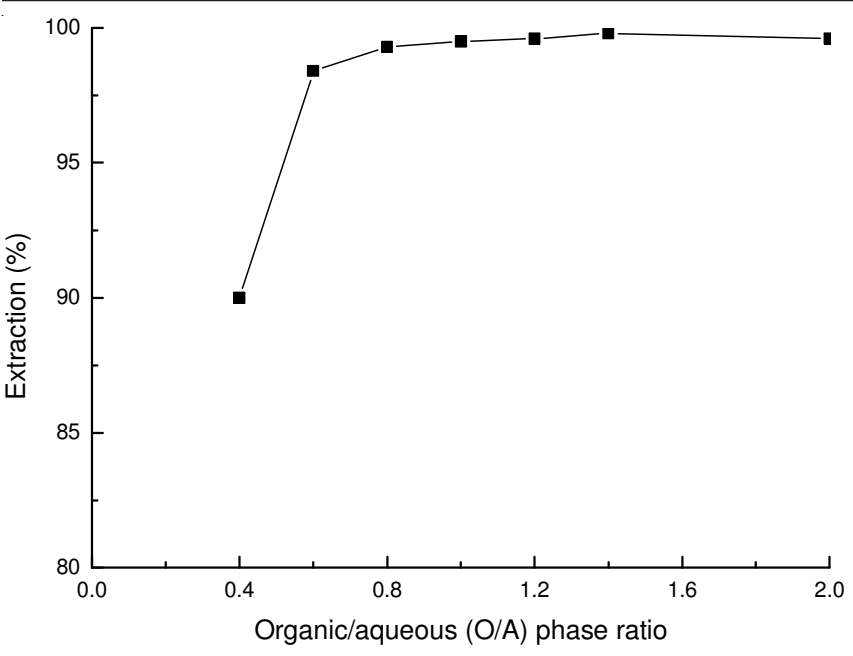

Fig. 4. Effect of $\mathrm{O} / \mathrm{A}$ on the extraction of $\mathrm{Pd}(\mathrm{II}) . \mathrm{C}_{\mathrm{Pd}(\mathrm{II})}: 100 \mathrm{mg} \mathrm{L}^{-1}, \mathrm{C}_{\mathrm{DIS}}$ : $0.008 \mathrm{~mol} \mathrm{~L}^{-1}$, contact time: $15 \mathrm{~min}, \mathrm{C}_{\mathrm{HCl}}: 0.1 \mathrm{~mol} \mathrm{~L}^{-1}$

agents. In the following experiments, the organic phase loaded with $100 \mathrm{mg} \mathrm{L}^{-1} \mathrm{Pd}(\mathrm{II})$ was used. The experiments were carried out at the following fixed parameters: contact time of the two phases, $15 \mathrm{~min}$; organic/aqueous $(\mathrm{O} / \mathrm{A})$ phase ratio, 1.0. The results show that palladium can not be stripped from organic phase with acid solution and sodium sulfite. Ammonia solution can be used as the effective stripping agent. As can be seen from Fig. 5, by increasing ammonia concentration from 0.1 to $1.0 \%(\mathrm{v} / \mathrm{v})$, the percentage stripping of $\mathrm{Pd}(\mathrm{II})$ increased from 51.9 to $96.4 \%$. By further increasing concentration of ammonia from 1.0 to $2.0 \%(\mathrm{v} / \mathrm{v})$, the percentage stripping of $\mathrm{Pd}(\mathrm{II})$ kept constant. The stripping was quantitative when $1 \%(\mathrm{v} / \mathrm{v})$ ammonia solution was used.

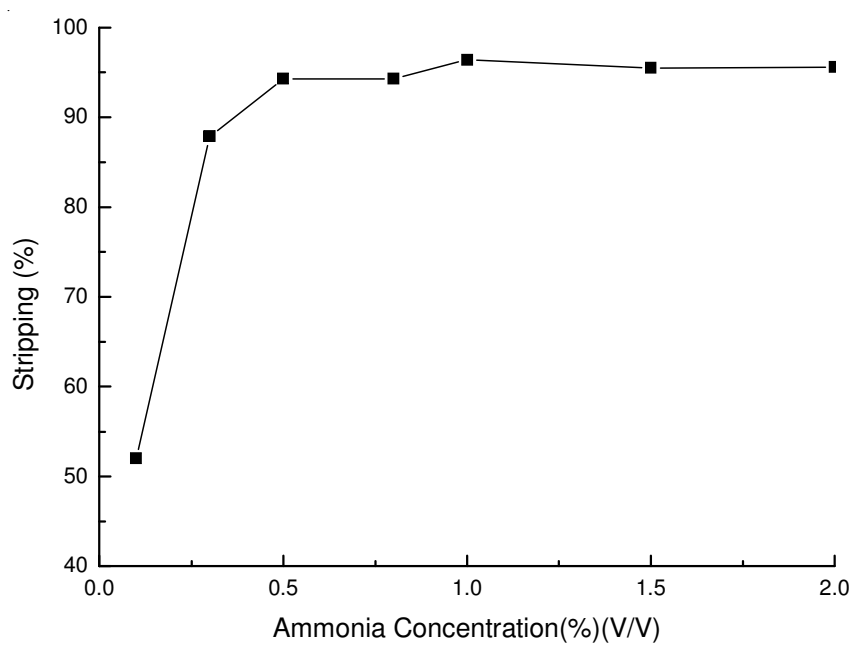

Fig. 5. Effect of stripping reagent concentration on the stripping of $\mathrm{Pd}(\mathrm{II})$. $\mathrm{C}_{\mathrm{Pd}(\mathrm{II})}: 100 \mathrm{mg} \mathrm{L}^{-1}, \mathrm{C}_{\mathrm{DIS}}: 0.008 \mathrm{~mol} \mathrm{~L}^{-1}, \mathrm{O} / \mathrm{A}: 1.0$, contact time: $15 \mathrm{~min}$

IR spectra of extracted Pd(II)-DIS complex: Extracted Pd(II)-DIS adduct may be prepared by following procedure: $0.2 \mathrm{~mol} \mathrm{~L}^{-1}$ DIS in kerosene was shaken with Pd(II) aqueous solution $\left(1.0 \mathrm{~g} \mathrm{~L}^{-1}\right.$ in $\left.0.1 \mathrm{M} \mathrm{HCl}\right)$ many times until a saturated extraction organic phase was obtained. Fig. 6 shows the IR spectra of DIS and Pd(II)-DIS complex. The C-S stretching vibration observed at $1460 \mathrm{~cm}^{-1}$ for DIS is shifted to $1450 \mathrm{~cm}^{-1}$ in the Pd(II)-DIS complex. This fact indicated the DIS is coordinated with Pd(II) via sulphur atom.

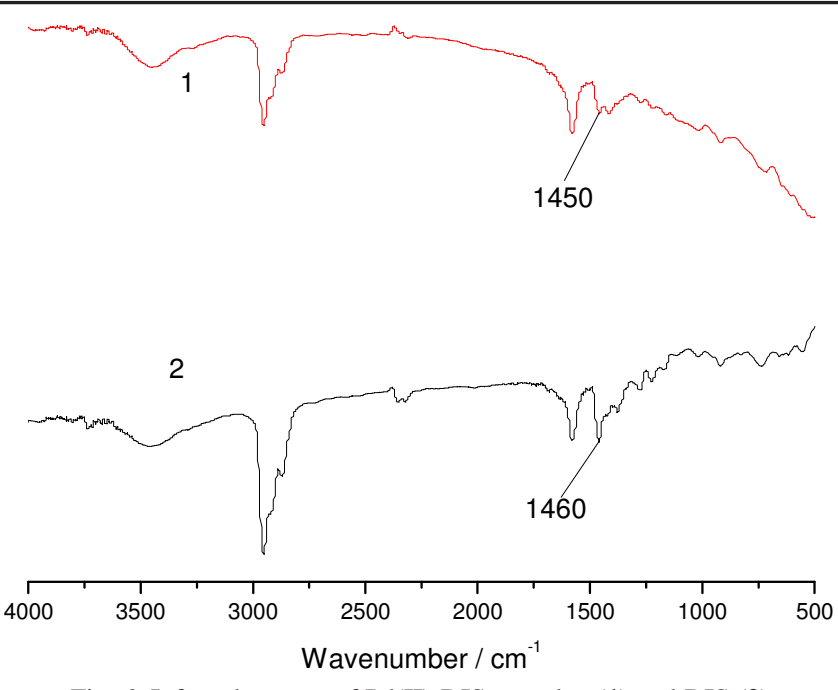

Fig. 6. Infrared spectra of Pd(II)-DIS complex (1) and DIS (2)

X-Ray crystallography of $\mathbf{P d}(\mathrm{DIS})_{2} \mathrm{Cl}_{2}$ : The crystal structure of $\mathrm{Pd}(\mathrm{DIS})_{2} \mathrm{Cl}_{2}$ is shown in Fig. 7. Crystallographic data and some experimental conditions used to obtain the intensity data are given in Table-1. As expected, in Pd(II)-DIS complex, DIS acts as neutral unidentate ligand coordinating to palladium via the sulphur atom. The complex is of transconformation and $\mathrm{Pd}(\mathrm{II})$ is coordinated by two $\mathrm{Cl}$ atoms and two DIS at opposite position. Two opposite $\mathrm{Pd}-\mathrm{S}$ and $\mathrm{Pd}-\mathrm{Cl}$ bond distances are equivalent, respectively. The $\mathrm{Pd}$-atom and two S-atoms are coplanar ( $\left.\mathrm{S}(1)-\mathrm{Pd}(1)-\mathrm{S}(1) \#=180.00^{\circ}\right)$. Thus, the palladium-DIS complex as a whole is in complete symmetry with palladium atom at the symmetry center of the square-planar complex.

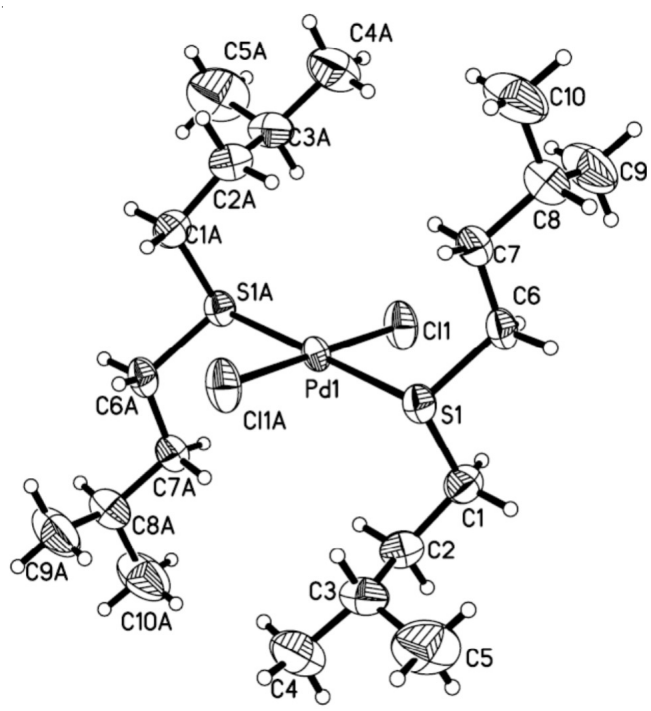

Fig. 7. Crystal structure of DIS-Pd(II)

\section{Conclusion}

The solvent extraction of $\mathrm{Pd}(\mathrm{II})$ from hydrochloric acid solutions were investigated using diisopentyl sulphide (DIS) diluted in kerosene. Extraction parameters of Pd(II) were obtained and summarized as the following: DIS concentration, 0.008 mol L ${ }^{-1}$; organic/aqueous $(\mathrm{O} / \mathrm{A})$ phase ratio, 1.0; hydrochloric acid concentration of aqueous solution, $0.1 \mathrm{~mol} \mathrm{~L}^{-1}$; contact 


\begin{tabular}{|c|c|}
\hline \multicolumn{2}{|c|}{$\begin{array}{c}\text { TABLE-1 } \\
\text { CRYSTAL DATA AND STRUCTURE } \\
\text { PARAMETERS FOR DIS-Pd(II) }\end{array}$} \\
\hline Parameters & Data \\
\hline Empirical formula & $\mathrm{C}_{20} \mathrm{H}_{44} \mathrm{Cl}_{2} \mathrm{PdS}_{2}$ \\
\hline Formula weight & 525.97 \\
\hline Temperature & 293(2) K \\
\hline Wavelength & $0.71073 \AA$ \\
\hline Crystal system & Monoclinic \\
\hline Space group & $\mathrm{P} 2(1) / \mathrm{c}$ \\
\hline Unit cell dimensions & $\begin{array}{l}\mathrm{a}=12.0690(14) \AA \alpha=90^{\circ} \\
\mathrm{b}=10.9888(13) \AA \beta=99.5650(10) \AA \\
\mathrm{c}=10.3636(12) \AA \gamma=90^{\circ}\end{array}$ \\
\hline Volume & $1355.4(3) \AA^{3}$ \\
\hline $\mathrm{Z}$ & 2 \\
\hline Calculated density & $1.289 \mathrm{mg} / \mathrm{m}^{3}$ \\
\hline $\mathrm{F}_{(000)}$ & 552 \\
\hline Crystal size & $0.36 \mathrm{~mm} \times 0.18 \mathrm{~mm} \times 0.06 \mathrm{~mm}$ \\
\hline $\begin{array}{l}\text { Theta range for data } \\
\text { collection }\end{array}$ & $1.71-28.15^{\circ}$ \\
\hline Reflections collected & 8117 \\
\hline Goodness-of-fit on $\mathrm{F}^{2}$ & 1.008 \\
\hline Final $R$ indices $[\mathrm{I}>2 \sigma(\mathrm{I})]$ & $\mathrm{R}_{1}=0.0350, \mathrm{wR}_{2}=0.0729$ \\
\hline $\mathrm{R}$ indices (all data) & $R_{1}=0.0632, w R_{2}=0.0868$ \\
\hline Largest diff. peak and hole & 0.726 and $-0.696 \mathrm{e} \AA^{-3}$ \\
\hline
\end{tabular}

time of two phases $15 \mathrm{~min}$. Pd(II) loaded in organic phase could be stripped efficiently using an ammonia solution. X-Ray crystal structure determination revealed $\mathrm{Pd}(\mathrm{DIS})_{2} \mathrm{Cl}_{2}$ square-planar complex in which DIS acts as a neutral unidentate ligand coordinated with palladium(II) via the $\mathrm{S}$ atom of the DIS.

\section{ACKNOWLEDGEMENTS}

This work was supported by the National Natural Science Foundation of China (51264038), Key Natural Science Foundation of China (U0937601), Development Program of China (2011AA03A405D) and Science and Technology Support Program of China (2008BAB32B10).

\section{REFERENCES}

1. A. Cieszynska and M. Wisniewski, Sep. Purif. Technol., 80, 385 (2011).

2. J. Traeger, J. Konig, A. Stadtke and H.J. Holdt, Hydrometallurgy, 127-128, 30 (2012).

3. J.M. Sanchez, M. Hidalgo and V. Salvado, Solvent Extr. Ion Exch., 22, 285 (2004)

4. A. Cieszynska and M. Wisniewski, Hydrometallurgy, 113-114, 79 (2012).

5. R. Kumaresan, K.N. Sabharwal, T.G. Srinivasan, P.R.V. Rao and G. Dhekane, Solvent Extr. Ion Exch., 26, 643 (2008).

6. S.P. Feng, Z.J. Huang and P.W. Li, Asian J. Chem., 23, 2605 (2011).

7. P. Malik and A.P. Paiva, Solvent Extr. Ion Exch., 28, 49 (2010).

8. F.L. Bernardis, R.A. Grant and D.C. Sherrington, React. Funct. Polym., 65, 205 (2005).

9. P.P. Sun and M.S. Lee, Hydrometallurgy, 109, 181 (2011).

10. B. Swain, J. Jeong, S.K. Kim and J.C. Lee, Hydrometallurgy, 104, 1 (2010).

11. B.R. Reddy, B. Raju, J.Y. Lee and H.K. Park, J. Hazard. Mater., 180, 253 (2010).

12. M. Rovira, J.L. Cortina and A.M. Sastre, Solvent Extr. Ion Exch., 17, 333 (1999).

13. Y.W. Li, G.B. Gu, H.Y. Liu, H.H.Y. Sung, I.D. Williams and C.K. Chang, Molecules, 10, 912 (2005).

14. L. Pan and Z.D. Zhang, Miner. Eng., 22, 1271 (2009).

15. J.Y. Lee, B. Raju, B.N. Kumar, J.R. Kumar, H.K. Park and B.R. Reddy, Sep. Purif. Technol., 73, 213 (2010).

16. J. Traeger, T. Klamroth, A. Kelling, S. Lubahn, E. Cleve, W. Mickler, M. Heydenreich, H. Muller and H.J. Holdt, Eur. J. Inorg. Chem., 2012, 2341 (2012). 